\title{
Do Circumstances of the Death Matter? Identifying Socioenvironmental Risks for Grief-Related Psychopathology in Bereaved Youth
}

\author{
Julie B. Kaplow, ${ }^{1}$ Kathryn H. Howell, ${ }^{2}$ and Christopher M. Layne ${ }^{3}$ \\ ${ }^{1}$ Department of Psychiatry, University of Michigan Medical School, Ann Arbor, Michigan, USA \\ ${ }^{2}$ Department of Psychology, University of Memphis, Memphis, Tennessee, USA \\ ${ }^{3}$ UCLA/Duke University National Center for Child Traumatic Stress, Department of Psychiatry and Biobehavioral Sciences, \\ University of California, Los Angeles, California, USA
}

\begin{abstract}
We examined bereaved children's and surviving caregivers' psychological responses following the death of the other caregiver as a function of the stated cause of death. Participants included 63 parentally bereaved children and 38 surviving caregivers who were assessed using self-report instruments and in-person interviews. Surviving caregivers reported the causes of death as resulting from sudden natural death $(34.9 \%)$, illness $(33.3 \%)$, accident $(17.5 \%)$, and suicide $(14.3 \%)$. Results revealed differences between caregiver-reported versus childreported cause of death, particularly in cases of suicide. Children who lost a caregiver due to a prolonged illness exhibited higher levels of both maladaptive grief $(d=3.13)$ and posttraumatic stress symptoms (PTSS; $d=3.33)$ when compared to children who lost a caregiver due to sudden natural death (e.g., heart attack). In contrast, surviving caregivers did not differ in their levels of maladaptive grief and PTSS as a function of the cause of death; however, caregivers bereaved by sudden natural death reported higher levels of depression than those bereaved by prolonged illness $(d=1.36)$. Limited sample size prevented analysis of outcomes among those bereaved by suicide or accident. These findings suggest that anticipated deaths may contain etiologic risk factors for maladaptive grief and PTSS in children.
\end{abstract}

Although parental loss in childhood has been identified as a prevalent and significant public health problem (UNAIDS, UNICEF, \& USAID, 2004), the field of childhood bereavement has remained in its infancy (Kaplow, Layne, Pynoos, Cohen, \& Lieberman, 2012). This is especially evident when benchmarked in terms of the modest advances the field has made in

This research was supported in part by grants NIMH K08 MH76078, the Todd Ouida Clinical Scholars Award, the Laurence Polatsch Memorial Fund, the Lynn Wilson Memorial Fund, and the Rachel Upjohn Clinical Scholars Award given to the first author. Drs. Layne and Kaplow hold proprietary rights to the Persistent Complex Bereavement Disorder Checklist-Youth Version 1.0 and Adult Version 1.0, as well as the Bereavement Risk and Resilience Index. The authors wish to thank Michelle Belke, Alena Grieser, Heather Hammerstrom, Harriett Jones, Georgia Stamatopoulos, and Amanda Tarantowski for their assistance with conducting interviews. We also thank Amanda Burnside, Emilie Lerner, and Britney Wardecker for their assistance with project coordination and Valerie Elsesser, Kara Koppinger, Mirele Mann, and Meredith Merlanti for their assistance with data management and data entry. We also wish to thank Irwin Sandler, Tim Ayers, and Albert Cain for their guidance regarding study design. Finally, we wish to acknowledge the Gilda's Club of Grand Rapids staff for their administrative support, and all participating children and caregivers.

Correspondence concerning this article should be addressed to Julie B. Kaplow, Assistant Professor and Director, Trauma and Grief Center for Youth, Department of Psychiatry, University of Michigan, 4250 Plymouth Road, Ann Arbor, MI 48109-5765. E-mail: julieb@med.umich.edu

Copyright (c) 2014 International Society for Traumatic Stress Studies. View this article online at wileyonlinelibrary.com DOI: $10.1002 /$ jts. 21877 differentiating between adaptive versus maladaptive grief reactions in bereaved youth (Nader \& Layne, 2009).

The limited literature suggests that childhood bereavement is often associated with other risk factors (e.g., poverty; Kaplow, Saunders, Angold, \& Costello, 2010), but in and of itself does not generally pose serious long-term risks (Dowdney, 2000). A significant minority (approximately 10\%) of bereaved youth, however, appear to experience grief reactions of sufficient severity to produce clinically significant impairment (Melhem, Porta, Shamseddeen, Walker Payne, \& Brent, 2011). Nevertheless, the specific constellations of child-intrinsic and socioenvironmental factors that influence the origin and clinical course of maladaptive grief reactions over time remain largely unknown.

The adult grief literature provides only modest guidance in identifying factors that best differentiate between adaptive versus maladaptive grief in childhood. Much of the recent discourse in the adult literature has focused on the duration of grief reactions per se (i.e., defining pathology in quantitative terms, such as prolonged grief reactions persisting for over 1 year; e.g., Prigerson et al., 2009). Conversely, less attention has been directed towards evaluating potential etiologic risk factors for maladaptive grief, including the stated cause of death.

Findings are mixed regarding the relative contribution to postloss adjustment of the stated cause of death of a close person. The few adult studies to date that evaluate the potential role 
of the manner of death have reported significantly higher prevalence of rates of "prolonged" or "complicated" grief among individuals bereaved as a result of sudden deaths (e.g., homicide, suicide, accidental death; Currier, Holland, \& Neimeyer, 2006; Rynearson \& Salloum, 2011). Violent deaths have also been associated with increased anxiety, depression, and maladaptive grief in adolescents (Dillen, Fontaine, \& VerhofstadtDeneve, 2009; Layne et al., 2008). In contrast, some studies (e.g., Brown et al., 2008) report nonsignificant associations between the cause of the death and maladaptive grief reactions in youth. For example, Melhem, Moritz, Walker, Shear, and Brent (2007) reported that complicated grief scores of youth bereaved by a caregiver's suicide did not significantly differ from those bereaved by sudden natural deaths (e.g., heart attacks).

Although few studies explicitly examine associations between the stated cause of death and postdeath psychological functioning, a greater number of studies have called attention to ways in which traumatogenic factors embedded in the circumstances of the death can interfere with bereaved youths' ability to grieve in adaptive ways (e.g., Cohen, Mannarino, Greenberg, Padlo, \& Shipley, 2002; Furman, 1974; McClatchey \& Vonk, 2005). Pynoos (1992) described how children who witness gruesome death can suffer from recurrent intrusive images that interfere with positive reminiscing about the deceased. These observations have been reported and further developed in more recent work (e.g., Layne et al., 2008).

The current ambiguity surrounding the role that the cause of the death may play in childhood mental health outcomes may be largely attributable to methodological limitations (Nader \& Layne, 2009). A number of study designs (e.g., Brown \& Goodman, 2005; Melhem et al., 2007, 2011) did not include anticipated deaths (e.g., cancer), thereby precluding the ability to examine potential differences in grief reactions as a function of anticipated versus sudden deaths. Such exclusions are problematic from both methodological and theory-building perspectives.

Specifically, it is possible that traumatogenic (and otherwise pathogenic) features embedded in the circumstances surrounding anticipated deaths may be of equivalent or greater potency in inducing severe distress in bereaved youth than features found in sudden unexpected deaths (Kaplow et al., 2012; McClatchey \& Vonk, 2005; Saldinger, Cain, \& Porterfield, 2003). Indeed, the very nature of anticipated deaths may create more instances in which children are exposed to potentially disturbing elements (e.g., witnessing disturbing medical procedures and/or the dying person's progressive deterioration during repeated hospital visits) than they are to sudden deaths (e.g., witnessing a loved one being carried away by ambulance following a heart attack, being informed that a loved one has died in a car accident). Although children may respond differentially to the circumstances of the death compared to their surviving caregivers, little research has been conducted on this topic.

Children depend on surviving caregivers to clarify and validate the reality of the death, cofacilitate the grief process
(Shapiro, Howell, \& Kaplow, in press), and make meaning of the loss (Kaplow et al., 2012). Thus, how children respond to different types of deaths may reflect what children are told by their surviving caregivers about the specific cause. Caregivers may struggle with whether or how to tell their children about the true cause of death, especially when confronted with stigmatized deaths (e.g., suicide). Caregivers may also choose to distort or withhold facts about how the person died to protect the child, even if the child was directly exposed to the true cause. Although this phenomenon was described qualitatively over 30 years ago (Bowlby, 1979; Cain \& Fast, 1972), the frequency and circumstances under which mismatches between surviving caregivers' reports of the actual cause of death, and what children are told-as well as the psychological consequences of such discrepancies-have yet to be studied empirically.

Accordingly, the aim of this exploratory study was to identify potential links between parent and child reports of the cause of death of a caregiver and their respective mental health problems, including maladaptive grief reactions, posttraumatic stress symptoms (PTSS), and depression. Study questions included (1) what are the most common causes of death as reported by both surviving caregivers and their children, (2) what is the general correspondence between caregivers' and children's reports of the cause of death, (3) are some stated causes of death more likely than others to be linked to differences between reports from the caregiver and child, and (4) are different stated causes associated with mean differences in psychological distress in bereaved children and surviving caregivers.

\section{Method}

\section{Participants}

Participants were recruited from three Michigan counties through grief support organizations or bereavement programs at local hospitals. Inclusion criteria were (a) the child experienced the death of a primary caregiver within the previous 6 months, (b) the child was between the ages of 3 years and 12 years, and (c) the family spoke English. Children from the same family were eligible to participate. Children were excluded from the study if they were identified as having cognitive deficits severe enough to impact their understanding of study questions, based on caregiver reports during the recruitment process. In total, 53 families were identified as being eligible for the study by grief program staff. After receiving written permission to call each of the families, the project coordinator contacted them; of those contacted, 15 (28.3\%) declined participation, most frequently stating discomfort with interviewers asking direct questions about the death to the child. No demographic or cause of death information was collected from families who declined participation.

Participants consisted of 63 recently bereaved children ( $44.4 \%$ female) between the ages of 3 years and 13 years $(M$ $=7.76$ years, $S D=2.91$ ) and their 38 surviving caregivers 
between the ages of 22 years and 64 years $(M=38.60, S D=$ 7.83). Of the 38 families who participated in the study, $60.5 \%$ were single-child homes and $39.5 \%$ were multiple-child homes. The average number of children per home was 1.66 (range $=1-$ 5 children). Racial/ethnic composition of children was $73.2 \%$ Caucasian, 12.2\% African American, 9.8\% Asian, 2.4\% Hispanic, and $2.4 \%$ Other. Of surviving caregivers, $81.6 \%$ were female, and $92.1 \%$ were a biological caregiver of the bereaved child. In $79.4 \%$ of the sample, the deceased caregiver was the child's biological father. Average elapsed time since the caregiver's death was 88.90 days $(S D=55.24)$. The racial composition of participating caregivers was the same as their children. Participating caregivers provided informed consent, and children gave verbal assent. The University of Michigan Medical School Institutional Review Board approved this project.

\section{Procedures}

Adult and child subjects participated in separate semistructured interviews regarding their recent loss experiences. In addition, all caregivers, and all children aged 7 years or older, completed a battery of questionnaires. Of the complete sample of 63 children, 41 were aged 7 or older $(M=9.40$ years, $S D=1.98)$ and thus completed study questionnaires. Of these 41 children, $47.6 \%$ were females. All questionnaire items were read aloud to children to enhance comprehension. Interviewers were master's-level clinicians experienced in working with bereaved families. A licensed clinical child psychologist (JBK) trained and supervised all study interviewers and (to ensure fidelity and appropriate administration of measures) held formal trainings on measure administration, reviewed videotapes of the interviews, and provided direct feedback in meetings with study interviewers. All interviews were videotaped and appraised for quality assurance. All participants received monetary compensation.

\section{Measures}

Caregiver interviews included questions pertaining to background and family history (e.g., child age, race, caregiver education, etc.). Caregivers and children responded independently to an open-ended question regarding the cause of the deceased caregiver's death (i.e., "How did ___ die?"). Responses were coded and assigned to one of six mutually exclusive categories by the trained project coordinator, including four causes of death (sudden natural death, anticipated death by illness, accident, suicide) and two other options ("I don't know"; "I forgot"). A separate study team member independently categorized all responses to this question to check accuracy and interrater reliability. Interrater agreement was 100\%.

We used the Negative Life Events Scale, a 54-item caregiver self-report measure of life stress developed specifically for bereaved families that has been used in other studies of bereaved youth (Sandler et al., 1992). We eliminated 18 items to decrease redundancy with other life event measures used in the study, creating a 36-item scale. In completing the Negative Life Events Scale, caregivers indicated whether a specified stressful life event had occurred to their child since the death. Events included death-related adversities (e.g., "other kids teased your child because of his/her caregiver's death") and other stressors (e.g., "your child changed schools"). Endorsed items ( 1 = event happened; $0=$ event did not happen) were summed to create a total life stress score.

We used the 36-item Inventory of Complicated Grief-Revised (Melhem et al., 2007) to measure child maladaptive grief. The Inventory of Complicated Grief-Revised is adapted from the Inventory of Complicated Grief, a test originally developed and validated with conjugally bereaved adults (Prigerson et al., 1995). Items (e.g., "The death of my mom/dad feels upsetting, overwhelming, or devastating") are rated on a 5-point scale ranging from $0=$ almost never to $4=$ always. Melhem et al. (2007) report modifying the wording of selected original items to enhance developmental appropriateness, pilot-testing the modified version with a clinical sample of eight youths bereaved by parental suicide, and factor analyzing the scores (producing a 3-factor solution). To adhere to Melhem et al.'s (2007) recommended scoring procedure and to enhance cross-study comparability, we summed all items to create a Total Maladaptive Grief score $(\alpha=.94$ in this sample).

We used the PG-13 (Prigerson et al., 2009) to assess maladaptive grief in caregivers. The PG-13 is derived from proposed diagnostic criteria for Prolonged Grief Disorder and covers 13 of the proposed symptoms. Items (e.g., "Since the time of your loss, how often have you felt yourself longing or yearning for the person who died?") are rated on a 5-point scale ranging from $1=$ never $/$ not at all to $5=$ several times a day/severe. All items are summed to create a total score $(\alpha=.81$ in this sample).

We used the 35-item UCLA PTSD Reaction Index Elhai et al. (2013) to assess child posttraumatic stress symptoms (PTSS) secondary to the death. Symptoms ("I have upsetting thoughts, pictures, or sounds of what happened come into my mind when I do not want them to") are rated on a 5-point scale from $0=$ never happens to $4=$ happens most of the time. All items are summed to create a total severity score $(\alpha=.91$ in this sample).

We used the Posttraumatic Stress Disorder Checklist-Civilian Version (PCL-C; Weathers, Huska, \& Keane, 1991) to assess PTSS in the surviving caregiver. This 17-item self-administered measure of all PTSD symptoms according to the Diagnostic and Statistical Manual of Mental Disorders (4th ed., DSMIV; American Psychiatric Association [APA], 1994) was also completed in relation to the death of the spouse. Items (e.g., "Repeated, disturbing memories, thoughts, or images of the death") are rated on a 5-point scale ranging from $1=$ not at all to $5=$ extremely and summed to create a total symptom severity score ( $\alpha=.89$ in this sample).

We used the 13-item Short Mood and Feelings Questionnaire (Angold et al., 1995) to assess child depressive symptoms. The 
Table 1

Cause of Death as Reported by Surviving Caregiver and Child

\begin{tabular}{|c|c|c|c|c|}
\hline \multirow[b]{2}{*}{ Cause of death } & \multicolumn{2}{|c|}{ Caregiver } & \multicolumn{2}{|c|}{ Child } \\
\hline & $n$ & $\%$ & $n$ & $\%$ \\
\hline Sudden natural & 13 & 34.9 & 21 & 33.3 \\
\hline Anticipated death by illness & 12 & 33.0 & 16 & 25.4 \\
\hline Accident & 8 & 17.5 & 12 & 19.0 \\
\hline Suicide & 5 & 14.3 & 5 & 6.0 \\
\hline Unknown cause & - & - & 7 & 11.0 \\
\hline Unable to recall cause & - & - & 2 & 1.6 \\
\hline
\end{tabular}

Note. $N=63$ bereaved children; 38 surviving caregivers.

frequency of depressive symptoms (e.g., "I felt miserable or unhappy") experienced during the last 2 weeks is rated on a 3 -point scale with options of $0=$ not true, $1=$ sometimes true, and $2=$ true. Responses are summed to create a total score $(\alpha=.81$ in this sample).

We used the Beck Depression Inventory II (BDI-II; Beck, Ward, Mendelson, Mock, \& Erbaugh, 1961), a 21-item selfadministered test of adult depressive symptoms, to assess caregiver depressive symptoms. Items cover various features of depression (e.g., "I can't get any pleasure from the things I used to enjoy"). Symptoms experienced during the past 2 weeks are rated on a 4-point scale ranging from $0=$ no evidence of symptom to $3=$ symptom experienced frequently and intensely and summed to create a total scale score $(\alpha=.89$ in this sample).

\section{Data Analysis}

Because multiple children from the same family were eligible to participate, we clustered child data by family. We used linear mixed modeling incorporating both fixed-effects parameters of covariates (e.g., cause of death reported by the surviving caregiver), as well as random effects (e.g., within-family clustering) in which within-family outcomes were treated as nonindependent observations. Because caregiver data were not clustered by family, we treated them as independent observations and used independent-samples $t$ tests for all caregiver analyses. We used SPSS 18.0 for all analyses.

\section{Results}

Table 1 presents frequencies of reported causes of death of the deceased caregiver according to both children's and surviving caregiver's reports in the complete sample (Question 1). Children reported the most frequent cause of death as sudden natural death (e.g., stroke, heart attack), followed by anticipated death due to illness (e.g., cancer), accidental death, and suicide. Notably, seven children reported not knowing the cause of death, and two children stated they could not recall the cause of death. Caregivers reported the primary cause of death as sudden natural death, followed by illness, accident, and suicide.
Table 2

Descriptive Statistics for Loss Related Variables in Surviving Caregivers and Subsample of Children Aged 7 and Older

\begin{tabular}{lrr}
\hline Variable & $M$ & $S D$ \\
\hline Caregiver & & \\
PG-13 & 26.94 & 7.64 \\
PCL-C & 32.84 & 8.31 \\
BDI & 13.55 & 6.68 \\
NLES & 9.26 & 4.51 \\
Child & & \\
ICG-R & 55.90 & 28.83 \\
UCLA PTSD RI & 24.40 & 16.29 \\
SMFQ & 6.15 & 4.53 \\
\hline
\end{tabular}

Note. $n=41$ children 7 years or older; 38 surviving caregivers. PG-13 = Interview for Prolonged Grief Disorder; PCL-C $=$ Posttraumatic Stress Disorder Checklist-Civilian Version; BDI = Beck Depression Inventory; NLES = Negative Life Events Scale; ICG-R = Inventory of Complicated Grief-Revised; UCLA PTSD RI = UCLA PTSD Reaction Index; SMFQ = Short Mood and Feelings Questionnaire.

We then compared the cause of death as reported by the surviving caregiver to the cause as reported by the child in the full sample. Notably, $25.4 \%$ of child reports concerning the cause of death did not match caregiver reports (Question 2). This discrepancy was most pronounced in suicide deaths as reported by the caregiver, four out of five $(80.0 \%)$ of which did not match their child's report (Question 3). Specifically, of the five children bereaved by suicide, four reported either "I don't know" or "I don't remember" regarding the cause of death. Chi-square tests indicated that this parent-child discordance was not significantly associated with the child's age.

We then evaluated the strength of associations between (a) the reported cause of death, (b) child mental health outcomes, and (c) caregiver mental health outcomes (Question 4). We based these analyses on caregiver reports of cause of death to both maximize sample size (all caregivers provided a response) and because adult reports were more likely to be accurate. Given that only children aged 7 years or older completed questionnaires assessing mental health, the following analyses were limited to the subsample of 41 children in this older age bracket (see Table 2). Table 2 presents descriptive statistics for loss-related variables in the subsample. We compared only the Anticipated Death and Sudden Natural Death subgroups due to low-cell frequencies for deaths attributed to accident and suicide. Table 3 presents the mean scores and effect sizes of child and caregiver mental health outcomes by cause of death. Independent-samples $t$ tests and $\chi^{2}$ analyses revealed that demographic (race, gender, age) variables, time since loss, and negative life events were not significantly associated with any variables of interest $(p>$ .050). Thus, to increase parsimony and statistical power, we did not statistically control for these variables in subsequent analyses. 
Table 3

Means and Standard Deviations by Cause of Death and Comparison of Sudden Versus Anticipated Natural Death

\begin{tabular}{|c|c|c|c|c|c|c|c|c|c|c|}
\hline \multirow[b]{2}{*}{ Variable } & \multirow[b]{2}{*}{ Range } & \multicolumn{2}{|c|}{$\begin{array}{l}\text { Accident } \\
(n=6)\end{array}$} & \multicolumn{2}{|c|}{$\begin{array}{l}\text { Suicide } \\
(n=5)\end{array}$} & \multicolumn{2}{|c|}{$\begin{array}{l}\text { Sudden natural } \\
\text { death }(n=17)\end{array}$} & \multicolumn{2}{|c|}{$\begin{array}{l}\text { Anticipated } \\
\text { death by illness } \\
(n=13)\end{array}$} & \multirow[b]{2}{*}{$d$} \\
\hline & & $M$ & $S D$ & $M$ & $S D$ & $\mathrm{M}$ & $S D$ & $M$ & $S D$ & \\
\hline \multicolumn{11}{|l|}{ Child } \\
\hline ICG-R & $14-115$ & 47.17 & 22.60 & 81.16 & 20.63 & 44.28 & 25.23 & 70.54 & 26.71 & $3.13^{*}$ \\
\hline UCLA PTSD RI & $1-55$ & 21.00 & 6.89 & 37.40 & 14.15 & 17.04 & 13.03 & 32.11 & 16.59 & $3.33^{*}$ \\
\hline SMFQ & $0-19$ & 5.40 & 1.52 & 11.00 & 4.74 & 4.35 & 3.06 & 6.86 & 5.46 & 0.56 \\
\hline \multicolumn{11}{|l|}{ Caregiver } \\
\hline PG-13 & $12-48$ & 25.55 & 9.66 & 29.22 & 10.04 & 27.68 & 6.64 & 28.60 & 7.04 & 0.05 \\
\hline PCL-C & $17-58$ & 38.36 & 9.15 & 31.56 & 6.02 & 34.87 & 9.94 & 32.14 & 8.29 & 0.30 \\
\hline BDI & $1-31$ & 11.00 & 8.66 & 10.89 & 5.49 & 17.36 & 5.70 & 9.89 & 5.28 & $1.36^{* *}$ \\
\hline
\end{tabular}

Note. $(d)$ applies only to differences between sudden natural death and anticipated death by illness subgroups. ICG-R = Inventory of Complicated Grief-Revised; UCLA PTSD-RI = UCLA PTSD Reaction Index; SMFQ = Short Mood and Feelings Questionnaire; PG-13 = Interview for Prolonged Grief Disorder; PCL-C = Posttraumatic Stress Disorder Checklist-Civilian Version; BDI = Beck Depression Inventory.

$* p<.05 . * * p<.01$.

\section{Cause of Death and Maladaptive Grief Reactions}

A linear mixed model revealed significant between-group mean differences in children's maladaptive grief reactions $-t(17.45)$ $=2.21, p=.041, d=3.13$-between anticipated death by illness $(M=70.54, S D=8.62)$ versus sudden natural death $(M=44.28, S D=8.16)$. Children who lost a caregiver due to an illness exhibited higher levels of maladaptive grief reactions ( $\left.M_{\text {difference }}=26.26, S E=11.87\right)$ compared to children who lost a caregiver due to sudden natural death. In contrast, no statistically significant between-group mean differences were found in caregiver's grief reactions between anticipated death by illness $(M=27.36, S D=6.86)$ versus sudden natural death $(M=27.68, S D=6.64)$ of their spouse.

We also found a significant between-group difference in children's self-reported PTSS scores, $t(13.80)=2.35, p=.034$, $d=3.33$, between children exposed to anticipated death by illness $(M=32.11, S D=4.48)$ versus sudden natural death $(M=17.04, S D=4.58)$. Children who lost a caregiver due to anticipated death following prolonged illness exhibited higher levels of PTSS ( $\left.M_{\text {difference }}=15.07, S E=6.41\right)$ compared to children who lost a caregiver due to sudden natural death. Conversely, we found no significant differences in caregiver's PTSS between caregivers exposed to anticipated death by illness $(M=32.00, S D=8.98)$ versus sudden natural death $(M=$ 34.87, $S D=9.94)$.

We found no significant relations between child depressive symptoms and cause of death $(p>.050)$. In contrast, we found a significant between-group difference in caregiver depressive symptoms, $t(38)=-4.26, p<.001, d=1.36$, between the anticipated death by illness $(M=9.89, S D=5.28)$ versus sudden natural death groups $(M=17.36, S D=5.70)$. The mean depressive symptom score was significantly higher in surviving caregivers who lost a spouse due to a sudden natural death, as opposed to an anticipated death.

\section{Discussion}

The results of this exploratory study underscore the utility of clearly delineating the reported cause of the death of a loved one-including the potential etiologic roles of pathogenic elements embedded within the circumstances of the deathin relation to maladaptive grief reactions, PTSS, and depressive symptoms in bereaved youth and caregivers. If replicated, our findings carry implications for grief theory-building, risk screening, and intervention applications. Specifically, these findings challenge the widely held assumption that sudden deaths (heart attacks) are inherently traumatic, whereas anticipated deaths due to natural causes (cancer) are not (e.g., Rando, 1991). Although sudden deaths often involve traumatic circumstances, our results suggest that the converse may also be true for children - that more predictable deaths arising from natural causes may also contain pathogenic risk factors (Kaplow et al., 2012; Nader \& Layne, 2009).

A substantial minority (25.4\%) of caregivers and children did not agree on the stated cause of death. Discrepancies between caregiver and child reports of cause of death appeared primarily in the suicide death subgroup. Although there were relatively few cases of suicide deaths in this sample (which prevented testing for significant differences between this subsample and others), all children who experienced a suicide death exhibited elevated levels of PTSS and maladaptive grief comparable to children bereaved by anticipated deaths. This finding, although preliminary, suggests that these children may have some awareness of the actual cause of death despite caregivers' efforts to 
protect them from the emotional pain and stigmatization of having a parent die by suicide. Bowlby (1979) observes that caregivers often prevent their children from incorporating information concerning events that caregivers wish had never occurred. In cases of suicide, psychiatric symptoms in bereaved children often emerge in the context of distorted caregiver communication about the circumstances of the death (e.g., "No, you did not hear a gun shot. Your father died of a heart attack"; Cain \& Fast, 1972). Findings from the current study suggest the need for assessment tools that capture both caregiver and child reports of cause of death, and point to the role that discrepancies between caregivers' versus children's reports may play as markers of risk for poor outcomes in bereaved children.

Our findings are consistent with the conclusions of prior studies (Cohen et al., 2002; Dillen et al., 2009; Layne et al., 2008; Pynoos, 1992) that circumstances of the death are significantly linked to bereaved children's psychological functioning. Children aged 7 years and older who experienced the anticipated death of a loved one reported significantly higher levels of maladaptive grief and PTSS than children bereaved by a sudden, natural death. These findings differ from those obtained from the surviving caregivers, who reported experiencing greater depression when the death of their spouse was due to a sudden natural death. Surprisingly, few studies of bereaved adults have explicitly examined circumstances of the death in relation to depression or other postloss mental health outcomes. A notable exception is Ott, Lueger, Kelber, and Prigerson's (2007) study, which found higher rates of complicated grief in conjugally bereaved adults who experienced a sudden death as opposed to an anticipated death.

Our results suggest that school-aged children and adults may vary in the degree to which they experience the circumstances of the death as emotionally disturbing and potentially traumatic. These findings beg the question, "Why might children experience higher levels of psychological distress following an anticipated death versus a sudden natural death?" One possibility is that anticipated deaths may provide more instances of exposure to traumatic images and accompanying intrusive preoccupations that interfere with adaptive grief processes (McClatchey \& Vonk, 2005; Saldinger et al., 2003). For example, children may witness repeated instances of disturbing medical procedures, deterioration of the caregiver's functioning, or the ongoing distress of other family members while anticipating the loss. These experiences may be particularly disturbing to children given their limited ability to make sense of the observed physical changes taking place and the threatening nature of losing a caregiver (Kaplow et al., 2012). In addition, children who experience an anticipated death may be more likely to face secondary adversities (e.g., financial problems resulting from medical expenses); they may also be less likely to receive an outpouring of social support (including from their surviving caregivers) given the public perception that sudden deaths are more "traumatic" than anticipated deaths (Rando, 1991). In turn, attenuated levels of support and guidance by surviving caregivers and other adults may have serious consequences, given their essential role in helping children to navigate the grief process (Kaplow et al., 2012; Lieberman, Compton, Van Horn, \& Ghosh Ippen, 2003; Shapiro et al., in press).

The current lack of empirically supported conceptual distinctions between adaptive versus maladaptive grief is both a major impediment to, and a major research mandate for, advancing the field (Nader \& Layne, 2009). Guiding theory concerning the etiology of maladaptive grief plays a particularly indispensable role in developing measures of grief-related diagnostic constructs (Kaplow, Layne, Saltzman, Cozza, \& Pynoos, 2013). The arrival of Persistent Complex Bereavement Disorder (PCBD) in the Appendix of DSM-5 as an invitation for further research (APA, 2013) makes the theory-building focus of this study regarding the etiology of maladaptive grief especially timely. The need for theory-building research is underscored by evidence that grief in bereaved youth may constitute a multidimensional construct whose dimensions differentially relate to different causal precursors (Layne, Kaplow, \& Pynoos, 2012). Our findings concerning a rarely-studied candidate risk factor-cause of death - may carry important implications for detecting, assessing, and treating specific symptom domains of PCBD (e.g., circumstance-related distress) as manifested in youth.

Notably, PCBD includes a traumatic bereavement specifier that focuses on only two causes of death (homicide and suicide) hypothesized to contribute to circumstance-related distress (APA, 2013; Kaplow et al., 2012); conversely, it does not include anticipated losses due to illness. Consistent with the invitation to pursue PCBD as an object of serious scientific study, our results point to the potential utility of incorporating a broader range of both "expected" and "sudden" deaths across youth of different ages in future research to better evaluate the developmental appropriateness, manifestations, and validity of PCBD and of the specifier itself. Such efforts will not only better clarify the conditions under which a traumatic bereavement specifier is appropriate, but also the incremental utility of assessing circumstance-related distress as an important part of the phenomenology of maladaptive grief in bereaved youth.

To our knowledge, this is the first study to jointly examine: (a) potential associations between the specific cause of death (including anticipated deaths) and (b) grief-related mental health problems in (c) parentally bereaved school-aged children and their surviving caregivers in (d) the close aftermath of the caregiver's death. Study limitations include a comparatively small, racially homogenous, nonrandom sample of participants, which decreases the generalizability of the results. Our community-based sample also limits the generalizability of our findings to clinical populations. Larger samples will permit more in-depth analyses of other categories of death not fully explored in this study (homicide, suicide, accidental deaths), as well as improve the capacity to examine links between concordance rates between parents' versus children's reports of cause of death and their mental health outcomes. Our cross-sectional study design also precludes causal inference and underscores the need for longitudinal investigations, including detailed 
assessment of the nature of stressors (e.g., duration of time anticipating the death).

An additional limitation is that the test (Inventory of Complicated Grief-Revised) used to measure childhood maladaptive grief was originally developed and validated with samples of elderly conjugally bereaved adults (Shear et al., 2011), and was intended to capture complicated grief reactions only (Melhem et al., 2007). Given the limited item pool of the Inventory of Complicated Grief-Revised (Melhem et al., 2007, p. 498), the resulting restriction in the nature, valence, and range of item content prohibited us from capturing other potentially important domains of grief-including circumstance-related distress. Future studies may benefit from the use of theoretically grounded, developmentally informed assessment tools that capture not only the full spectrum of $D S M-5$ PCBD features, including the traumatic bereavement specifier (Kaplow et al., 2012; Nader \& Layne, 2009), but also circumstance-related distress and adaptive grief reactions across different types of death and developmental stages (e.g., Layne, Kaplow, \& Pynoos, 2011, 2013).

Although preliminary, the results of this study provide support for the theoretical proposition (see Kaplow et al., 2013) that the circumstances of the death do matter-particularly as gauged by children's grief and posttraumatic stress reactions, as well as caregivers' depression. Our findings run contrary to the widely held assumption that children bereaved by the anticipated death of a caregiver are likely to develop fewer mental health problems than children who suddenly lose a parent (e.g., Rando, 1991). Although many children bereaved by anticipated losses exhibit resilience, our results nevertheless raise questions concerning whether, and how, this subgroup could be at equivalent or greater risk for poor psychological outcomes than children bereaved under sudden circumstances. Replication studies of bereaved youth are needed across different populations, settings, and circumstances (including other types of sudden deaths, e.g., suicide, homicide, accidents) that employ more rigorous methods for "unpacking" circumstances of the death into candidate pathogenic elements and etiologic risk factors (Layne et al., 2010). Pursuant to this end, we are currently validating an applied clinical research tool, the Bereavement Risk and Resilience Index (Layne \& Kaplow, 2012; described in Kaplow et al., 2013), which consists of a broad assemblage of hypothesized risk, vulnerability, and protective factors culled from the empirical grief literature and derived from guiding multidimensional grief theory (Kaplow et al., 2013; Layne et al., 2012). We hope that the evidence base produced through more methodologically rigorous research designs will promote the development of clinically useful theory, developmentally appropriate assessment tools, and effective interventions needed to provide bereaved children and families with best-practice care.

\section{References}

American Psychiatric Association. (1994). Diagnostic and statistical manual of mental disorders ( $4^{\text {th }}$ ed.). Washington, DC: Author.
American Psychiatric Association. (2013). Diagnostic and statistical manual of mental disorders (5th ed.). Washington, DC: Author.

Angold, A., Costello, E. J., Messer, S. C., Pickles, A., Winder, F., \& Silver, D. (1995). Development of a short questionnaire for use in epidemiological studies of depression in children and adolescents. International Journal of Methods in Psychiatric Research, 5, 237-249.

Beck, A. T., Ward, C. H., Mendelson, M., Mock, J., \& Erbaugh, J. (1961). An inventory for measuring depression. Archives of General Psychiatry, 4, 561-571. doi:10.1001/archpsyc.1961.01710120031004

Bowlby, J. (1979). On knowing what you are not supposed to know and feeling what you are not supposed to feel. The Canadian Journal of Psychiatry, 24, 403-408.

Brown, E. J., Amaya-Jackson, L., Cohen, J., Handel, S., Thiel De Bocanegra, H., Zatta, E., ... Mannarino, A. (2008). Childhood traumatic grief: A multisite empirical examination of the construct and its correlates. Death Studies, 32, 899-923. doi:10.1080/07481180802440209

Brown, E., \& Goodman, R. (2005). Childhood traumatic grief: An exploration of the construct in children bereaved on September 11. Journal of Clinical Child and Adolescent Psychology, 34, 248-259. doi:10.1207/s15374424jecp3402_4

Cain, A. C., \& Fast, I. (1972). Children's disturbed reactions to caregiver suicide: Distortions of guilt, communication and identification. In A. C. Cain (Ed.), Survivors of suicide (pp. 93-111). Springfield, IL: Charles C. Thomas.

Cohen, J. A., Mannarino, A. P., Greenberg, T. A., Padlo, S., \& Shipley, C. (2002). Childhood traumatic grief: Concepts and controversies. Trauma, Violence and Abuse, 3, 307-327. doi:10.1177/1524838002237332

Currier, J. M., Holland, J. M., \& Neimeyer, R. A. (2006). Sense-making, grief, and the experience of violent loss: Toward a mediational model. Death Studies, 30, 403-428. doi:10.1080/07481180600614351

Dillen, L., Fontaine, J. R., \& Verhofstadt-Deneve, L. (2009). Confirming the distinctiveness of complicated grief from depression and anxiety among adolescents. Death Studies, 33, 437-461. doi:10.1080/07481180902805673

Dowdney, L. (2000). Annotation: Childhood bereavement following parental death. Journal of Child Psychology and Psychiatry, 41, 819-830. doi:10.1111/1469-7610.00670

Elhai, J. D., Layne, C. M., Steinberg, A. M., Brymer, M. J., Briggs, E. C., Ostrowski, S. A., \& Pynoos, R. S. (2013). Psychometric properties of the UCLA PTSD Reaction Index. Part II: Investigating factor structure findings in a national clinic-referred youth sample. Journal of Traumatic Stress, 26, $10-18$.

Furman, E. (1974). A child's caregiver dies: Studies in childhood bereavement. New Haven, CT: Yale University Press.

Kaplow, J. B., Layne, C. M., Pynoos, R. S., Cohen, J., \& Lieberman, A. (2012). $D S M-V$ diagnostic criteria for bereavement-related disorders in children and adolescents: Developmental considerations. Psychiatry, 75, 243-266. doi:10.1521/psyc.2012.75.3.243

Kaplow, J. B., Layne, C. M., Saltzman, W. R., Cozza, S. J., \& Pynoos, R. S. (2013). Using multidimensional grief theory to explore the effects of deployment, reintegration, and death on military youth and families. Clinical Child and Family Psychology Review, 16, 322-340. doi:10.1007/s10567013-0143-1

Kaplow, J. B., Saunders, J., Angold, A., \& Costello, E. J. (2010). Psychiatric symptoms in bereaved versus nonbereaved youth and young adults: A longitudinal epidemiological study. Journal of the American Academy of Child \& Adolescent Psychiatry, 49, 1145-1154. doi:10.1097/00004583-20101100000008 
Layne, C. M., \& Kaplow, J. B. (2012). Bereavement Risk and Resilience Index (BRRI). Unpublished psychological test, University of California, Los Angeles.

Layne, C. M., Kaplow, J. B., \& Pynoos, R. S. (2012, November). Using developmentally-informed theory and evidence-based assessment to guide intervention with bereaved youth and families. Symposium presented at the Annual Meeting of the International Society for Traumatic Stress Studies, Los Angeles, CA.

Layne, C. M., Kaplow, J. B., \& Pynoos, R. S. (2011). The Multidimensional Grief Reactions Scale-youth version 1.0. Psychological assessment test, University of California, Los Angeles.

Layne, C. M., Kaplow, J. B., \& Pynoos, R. S. (2013). The Persistent Complex Bereavement Disorder Checklist-youth version 1.0. Psychological assessment test, University of California, Los Angeles.

Layne, C. M., Olsen, J. A., Baker, A. Legerski, J. P., Isakson, B., Pašalić, A., ... Pynoos, R. S. (2010). Unpacking trauma exposure risk factors and differential pathways of influence: Predicting post-war mental distress in Bosnian adolescents. Child Development, 81, 1053-1076. doi:10.1111/j.1467-8624.2010.01454.x

Layne, C. M., Saltzman, W. R., Poppleton, L., Burlingame, G. M., Pašalić, A., Durkavović, E., ... Pynoos, R. S. (2008). Effectiveness of a schoolbased group psychotherapy program for war-exposed adolescents: A randomized controlled trial. Journal of the American Academy of Child and Adolescent Psychiatry, 47, 1048-1062. doi:10.1097/CHI.0b013e31817 eecae

Lieberman, A. F., Compton, N. C., Van Horn, P., \& Ghosh Ippen, C. (2003). Losing a caregiver to death in the early years: Guidelines for the treatment of traumatic bereavement in infancy and early childhood. Washington, DC: Zero to Three.

McClatchey, R. S., \& Vonk, M. E. (2005). An exploratory study of posttraumatic stress disorder symptoms among bereaved children. Omega Journal of Death and Dying, 51, 285-300.

Melhem, N. M., Moritz, G., Walker, M., Shear, M. K., \& Brent, D. (2007). Phenomenology and correlates of complicated grief in children and adolescents. Journal of the American Academy of Child and Adolescent Psychiatry, 46, 493-499. doi:10.1097/chi.0b013e31803062a9

Melhem, N. M., Porta, G., Shamseddeen, W., Walker Payne, M., \& Brent, D. A. (2011). Grief in children and adolescents bereaved by sudden parental death. Archives of General Psychiatry, 68, 911-919. doi:10.1001/archgenpsychiatry.2011.101

Nader, K. O., \& Layne, C. M. (2009). Maladaptive grieving in children and adolescents: Discovering developmentally linked differences in the manifestation of grief. Stress Points, 23(5), 12-15.
Ott, C. H., Lueger, R. J., Kelber, S. T., \& Prigerson, H. G. (2007). Spousal bereavement in older adults: Common, resilient, and chronic grief with defining characteristics. Journal of Nervous and Mental Disease, 195, 332341. doi:10.1097/01.nmd.0000243890.93992.1e

Prigerson, H. G., Horowitz, M. J., Jacobs, S. C., Parkes, C. M., Aslan, M., Goodkin, K., . . . Maciejewski. (2009). Prolonged grief disorder: Psychometric validation of criteria proposed for DSM-V and ICD-11. Public Library of Science, 6(8), e1000121. doi:10.1371/journal.pmed.1000121

Prigerson, H. G., Maciejewski, P. K., Reynolds, C. F. III, Bierhals, A. J., Newsom, J. T., Fasiczka, A., ... Miller, M. (1995). The inventory of complicated grief: A scale to measure maladaptive symptoms of loss. Psychiatry Research, 59(1-2), 65-79.

Pynoos, R. S. (1992). Grief and trauma in children and adolescents. Bereavement Care, 11, 2-10. doi:10.1080/02682629208657280

Rando, T. (1991). How to go on living when someone you love dies. New York, NY: Bantam Books.

Rynearson, E. K., \& Salloum, A. (2011). Restorative retelling: Revising the narrative of violent death. In R. A. Neimeyer, D. L. Harris, H. R. Winokuer, \& G. F. Thornton (Eds.), Grief and bereavement in contemporary society: Bridging research and practice (pp. 177-188). New York, NY: Routledge.

Saldinger, A., Cain, A., \& Porterfield, K. (2003). Managing traumatic stress in children anticipating parental death. Interpersonal and Biological Processes, 66, 168-181. doi:10.1521/psyc.66.2.168.20613

Sandler, I. N., West, S. G., Baca, L., Pillow, D. R., Gersten, J., Rogosch, F., . . . Ramirez, R. (1992). Linking empirically based theory and evaluation: The Family Bereavement Program. American Journal of Community Psychology, 20,491-521. doi:10.1007/BF00937756.

Shapiro, D. N., Howell, K. H., \& Kaplow, J. B. (in press). Associations among mother-child communication quality, childhood maladaptive grief, and depressive symptoms. Death Studies. doi:10.1080/07481187.2012. 738771

Shear, M. K., Simon, N., Wall, M., Zisook, S., Neimeyer, R., Duan, N.,... Keshaviah, A. (2011). Complicated grief and related bereavement issues for DSM-5. Depression and Anxiety, 28, 103-117. doi: 10.1002/da.20780

UNAIDS, UNICEF, \& USAID. (2004). Children on the Brink 2004: A joint report on new orphan estimates and a framework for action. New York, NY: Author.

Weathers, F. W., Huska, J. A., \& Keane, T. M. (1991). The PTSD Checklist Civilian Version (PCL-C). Boston, MA: National Center for PTSDBehavioral Science Division. 